\title{
Life Cycle of Private Schools Experiencing Failure in Democratic Republic of Congo
}

\author{
Corneille Luboya Tshiunza ${ }^{1,2}$, Landry Kinkani Batekele ${ }^{3,4}$, Jean Paul Yawidi ${ }^{5}$ \\ ${ }^{1}$ School of Education, Central China Normal University, Wuhan, China \\ ${ }^{2}$ School of Psychology and Educational Sciences, National Pedagogical University, Kinshasa, Congo \\ ${ }^{3}$ School of Economics and Business Administration, Central China Normal University, Wuhan, China \\ ${ }^{4}$ School of Public Works, National Institute of Construction and Public Works, Kinshasa, Congo \\ ${ }^{5}$ School of Psychology and Educational Sciences, National Pedagogical University, Kinshasa, Congo \\ Email: corneilleluboya@outlook.fr
}

How to cite this paper: Tshiunza, C.L., Batekele, L.K. and Yawidi, J.P. (2017) Life Cycle of Private Schools Experiencing Failure in Democratic Republic of Congo. Open Journal of Social Sciences, 5, 318-342. https://doi.org/10.4236/jss.2017.510027

Received: September 22, 2017

Accepted: October 28, 2017

Published: October 31, 2017

Copyright (c) 2017 by authors and Scientific Research Publishing Inc. This work is licensed under the Creative Commons Attribution International License (CC BY 4.0).

http://creativecommons.org/licenses/by/4.0/

\begin{abstract}
Over 217 private schools were surveyed on bankruptcy or failure in the Educational Province of Kinshasa-West between 2007 and 2012 in DR Congo. This particular situation needs to be studied. This mixed methods study with triangulation allowed collection and exploitation of two types of data separately. The qualitative data were made up by the archives documents of the 140 schools. The quantitative data collected by survey (questionnaire) with 420 actors from these private schools respectively ex-schools' promoters, ex-teachers and ex-schools' principals. This sequential exploratory mixed methods study describes briefly some determinant factors of failure and categorize, classify and describe the characteristics of life cycle stages of these private schools' experiencing failure.
\end{abstract}

\section{Keywords}

School Failure or School Bankruptcy, Private School and Life Cycle of an Organization

\section{Introduction}

\subsection{Research Background}

Several studies are devoted to studying the life cycle and factors of the bankruptcy (Hersey, Kenneth and Blanchard, 1972; Chandler, 1962; Adizes I. 1998;; Quinn and Cameron, 1983; Blazy et Combier, 1998; Saporta, 1994; Koenig, 1991; Luboya, 2010) [1]-[8]. However, few cases of these studies and academic reports were directed in educational sector. It is also necessary to note that few of these 
studies establish the contingency links between the life cycle and the determining factors of the bankruptcy of an organization. An effort should be emphases towards this direction to enrich the existence theories on the contingency approach of life cycle of an organization and to build a typology of the life cycle and the characteristics of its evolutionary phases. It is necessary to admit that the questions of bankruptcy of industries are obvious in the primary, secondary and service sector. This situation touches the local, provincial, national, regional and multinational industries or firms.

In Democratic Republic of Congo (DR Congo), the failure issues and bankruptcy of organizations or industries concern and touch all sectors of the national life. In the sector of education, the demand of education is higher than the offer. The statistics estimate more than 7,375,875 children and teenagers of 5 to 17 years olds are not attending school (RD Congo-MINESP, 2012) [9].

Facing this situation, some Congolese or religious organizations are authorized by the national law to create private schools and to make them approve by the State authority. In last decade, the initiatives of the schools creating or simple establishments of the school infrastructures are rarely in DR Congo. Among those created in the big cities of the countries, many do not fill all the guaranties material, human, juridical-administrative and psych pedagogic school factors of the reliability and the quality of the institution envisaged by the outline law of national education.

Indeed, the statistical data collected on the initiatives of the private schools in the educational Province of Kinshasa-West in 2012 reveal that each year, they record around 43 request files of creation and agreement of the private schools in each educational district. Every year, it reported the overgrowth of creation of private schools, however, in average 20 private schools surveyed on bankruptcy or failure. As a whole, in five years' time frame (from 2007 to 2012), it recorded more than 217 private schools experiencing failure.

\subsection{Research Questions and Hypothesis}

This mixed study answer the following questions: How do the models of life cycle of these private schools from the point of view of their duration and stages present? Does the failure have a significant relation with the environment, the size, the age or model of life cycle of these private schools?

This study verifies the following hypothesis:

- The schools experiencing failure would have differently lived the model of life cycle according to the phases. The majority of these schools were lived a complete life cycle. About the duration of life cycle, these schools lived in short term, medium-term and long term.

- Compared to their degree of preponderance, various factors related to the problems of the school operation and resources management, the school organization, the school design and requirement creation, the exceptional situations and unforeseeable would explain the situation of these private schools 
experiencing failure. The failure of schools would not depend significantly on the seniority, of the studies level and function assumed by school promoters, principals and teachers; it would not depend significantly on their size, environment, school level organized and model of school life cycle.

\subsection{Significance and Purpose Statement of Study}

Taking in account of the high rate of private schools experiencing failure in DR Congo, this study contributes to the examination of this situation. There are theoretical and social-political significance of this study.

Theoretically, this study explains empirically the model of explanation of life cycle of the private schools experiencing failure. The results of this study constitute a reference for future research in particular. And explain the various factors of the failure of school on the life cycle perspective. A methodological interest is in the development of an effective strategy based on the mixed method and of the triangulation.

Practically, this study is a contribution to the various actors and educational partners in DR Congo. It acts, as a tool for sensitizing of the school authorities, educational operators from the strategic level, hierarchical line, techno structure and operational center of the educational sector in general and school government local level as well public as private and to lay out relevant information likely to understand and make a good interpretation of the school life cycle.

This mixed methods study associated with the triangulation has purpose to identify, categorize and describe the characteristics of the various phases of life cycle of private schools experiencing failure in Kinshasa (DR Congo) and to explain the failure of these schools. The qualitative data from biographical or historical documents of these disappeared schools was collected and allow us to build and test a theory on the life cycle lived by these schools. The quantitative data also was collected and exploited in order to test the theory of contingency which predicts, the influence (positive or negative) in the phases of the school life cycle controlled by the environment, the size and the organized level school; another dimensions impact (significant or not) of the seniority, of studies level and function assumed by schools actors on the bankruptcy of these schools controlled by the size, the environment and the organized level of school. This is why the mixed method, qualitative and quantitative data-gathering prove of great importance.

\section{Theoretical Perspective}

\subsection{School Failure or School Bankruptcy}

\subsubsection{Parallelism between Failure and Bankruptcy}

The failure is the situation from which a procedure of rectification is opened against a company. This procedure must be put in work, as soon as the company is in a state of suspension of payment. The companies can also disappear apart from the framework from a collective procedure, with continuation of a decision 
of its leaders. They can choose to liquidate it, yield it in its totality or simply to separate from branches of activity in a procedure of scission, to accept that it is the object of a procedure of fusion, and even to simply close it purely and by putting an end to its activity (Blazy and Combier, 1998) [5]. In theory one opposes the companies which are the object of a collective procedure to the other companies.

On the other hand, other authors limit the sample of the failing companies to those which went bankrupt. They then exclude from the population of the nonfailing companies, those which have a fragile financial health, in particular the vulnerable companies which answer a criterion broader than the simple non-payment, with an aim of obtaining more marked discrimination (Ooghe and Van Wymmersch, 1996) [10]. Other alternatives are possible, in this respect, the failure is a situation where financial and material resources generated by the companies does not make it possible to satisfy their commitments towards the financial partners and not-financial (Liang and Wu, 2003; Hol and Wijst, 2002) [11] [12].

However, the "failure" is being one of these three cases of figure: the activity of the company is discontinuous, either this activity does not release an adequate profitability, or it is the object of a legal declaration of insolvency (Sharabany, 2004) [13]. The first definition is not acceptable because it can be explained by other elements, in particular acquisition, fusion, etc. The second definition is applicable there because it gives an economic explanation of the failure; it is however about a subjective definition, because an adequate profitability is difficult to define, this is why one generally retains the legal aspect of the failure term.

A company is regarded as failing if the probability of defect calculated by the formula of Black and Scholes is higher than 1\%. It is moreover, interesting to note that in a recent publication (Abid and Zouari, 2001; Pompeand Bilderbeek, 2005; Pindado and Rodrigues, 2001). [14] [15] [16], the notion of the failure is largely related to the credit risk, because of the refusal of bank credit a company is declared insolvent by a bank (Atiya, 2001) [17].

The bankruptcy of the company is the situation in which there are no more available assets to cope with the eligible liability (Abid and Zouari, 2001) [14]. Generally, they are the leaders who decide to deposit a declaration of the bankruptcy of the company in front of the court. But, it also happens that the request for opening of a procedure emanates from an unpaid creditor. The bankruptcy of a company encompasses several concepts of which the suspension of payment or voluntary liquidation, rectification and compulsory liquidation. In the same way, the fail is the companies that ceased their activities and legally declare bankruptcy; loss their creditors caused; close voluntarily without entirely discharging their obligations; were implied in reorganizations; voluntary agreements of refunding with their creditors undertaken negotiated; Fail, the companies reached by a legal bankruptcy (Berryman, 1982) [18]. 
Many authors compare definitions of Beryman (1982) [18] to the bankruptcy. Even in the language of New Larousse encyclopedic (1994) [19] bankruptcy "is a situation, one period per which an organization or an organization is in complete failure". Thus, some specialists noted the important variations in the rate of failure following the definition used. He affirms that it is necessary to go bankrupt a distinction between failure and before formulating some conclusion that it is (Julien and Marchesnay, 1996) [20]. Because it is also possible to oppose the companies which knew a non-payment face those which went bankrupt, to the others (Julien and Marchesnay, 1996) [20]. The bankruptcy is a complete form of the failure. For one undertook, it is marked by a suspension of payment. Whereas the failure is a negative result about attempt or goal of organization or school.

We retain of it that the bankruptcy is a form of failure. In the framework of this work, we will choose the definition of Mayau, (1990) [21]. It takes all the companies not having answered its definition of success as those which failed. In this case, certain authors present the failure like a source of training. To locate the clear difference between these three concepts always dependent between them, we need to consider the divergence in these terms: "One should not confuse the concept of judgement of procedure of failure (voluntary liquidation of a company registered within the framework of a legal procedure which is not solved inevitably by a liquidation) and the broader concept of suspension (complete stop of the economic activity of a company). Liquidations following a failure represent only part of the whole of the suspensions of companies, about variable $20 \%$ but with the time and the branches of industry" (Blazy and Combier, 1998; Mayau, 1990) [5] [21].

On this, we can affirm that the bankruptcy (complete stop of the activity) is more serious than a simple suspension of the payments, than is the failure because this last can profit from a plan of continuation by files for bankruptcy and financial. Another differentiation is related to the fact that the bankruptcy is declared by the manager of a company and is officialized by a judgement of the county court at the clerk's office of which the consent must be made at the time when the simple failure is noted by the thirds when there is a deficit either of turnover, or of the exploitations or normal productions of a company. In this direction, the failure is not far from the failure because it is presented in the form of a simple failure of an attempt of the company.

\subsubsection{What Term Should Be Employed to Explain Disappeared School?} In general, the school experiencing failure is a popular expression often indicating criticisms addressed to the school in general or an education system because of its incapacity to achieve its social and educational mission. It acts, for example, the report of a school or an education system which accentuates the social inequalities and economic or its incapacity to make leave the outputs, end products, graduates likely to do favors for the company or simple maladjustments of its graduates to the market of employment. It is to say that the end products are 
useless to be consumed directly or indirectly. The educational level succeeded is neither equal nor higher than the international standard or a threshold, criterion acceptable. It is incapacity of school to meet the social requirement in qualified and qualified perspectives.

In this paper, the option of the concept "failure or bankruptcy" is not in this same direction. The failure is employed as a neologism because we know that science injects by time of new concept in the absence of an explicit term (suitable term) to explain a fact or authorizes the loan of term. As we further specified, the state of the bankruptcy of a company is evaluated by a bankruptcy court which files legal proceedings of rectification or liquidation starting from suspension of payment (disappear) of a company in the field commercial or according to the provisions of commercial law.

However, in the fields as of private schools in DR Congo, disappearance (suspension of the activities) inevitably does not involve the opening of a legal procedure to lead to a judgement of the bankruptcy by the bankruptcy court or of parquet floor of great authority although governed by the Labor Code but it is only the object either of retrocession of the heritage of the company, or simple closing down, or still the withdrawal of stops ministerial or of authorization of operation by the qualified school politico-administrative entities (Ministry, Educational Province or Under Educational Province) at the conclusion of the analysis of the reports of the meeting of school promotion at the national, provincial, under provincial levels.

It should be noted that in DR Congo, the private schools function by their own finances. One means the receipts carried out by the school fees paid by the parents of the pupils in exchanges of services of the education given to their children.

- In our study, we prefer the term "failure is using as bankruptcy in economic sector" compared to the characteristics of this concept, studied reality and the absence of a term adapts indicating at the same time death, the closing initiated by the school itself and disappearance. They are reasons among which:

- The bankruptcy or failure (complete stop of the activity) is more serious than a simple suspension of payments because the latter can profit from a plan of continuation by files for bankruptcy and financial; the establishments concerned actually stopped their activity, missing and closed down;

- The bankruptcy of a company recovers several concepts whose suspension of the activities, rectification and compulsory liquidation and schools targeted answer one of these concepts, the first;

- These schools were officially authorized to operate but disappeared after one period of activity even if it was short-term, average or long-term of their existence;

- In addition particular framework school law (RD Congo-MINESP, 2014) [22], the private schools also are under controls of Congolese Labor Code, 
their own statute and rules of procedure, and poured various taxes taxed specific to the private companies will extras school in DR Congo;

- The schools not only ceased their activity but really disappeared from their environment and in their installation;

- The disappearance of the schools is noted and attested by the qualified entities of the jurisdiction in charge of their management and their control.

Therefore, we use the concept "bankruptcy or failure" in our study not in its legal direction but as "neologism" in the absence of term adapted. Despite using of term bankruptcy or failure in commercial companies or industries (lucrative character), we use this term in the educational institution (private school experiencing failure).

According to Oogheand Van Wymmersch (1996) [10], the "bankruptcyor failure" is "a situation where the available assets do not make possible a company to cope with the eligible liability and death follows from there". Ultimately, in the light of the above-mentioned definitions, we think that the bankruptcy of the school or the school in bankruptcy can also be a complete failure, complete stop of the activities of a school, the incapacity to mobilize essential resources with its operation and to keep to its commitments declared by a person in charge of this one, noted and accredited by the qualified school entities within the competence of the known as establishment. It is also the complete stop of the activities of a school involving its physical disappear, the reference of its teaching staff, replacement of the pupils in other schools and given of the school archives to the decentralized school entities.

\subsection{Private School}

According to the Framework-Law of National Teaching (RD Congo-MINESP, 2014 in its article 7) [22], "an educational establishment or school is an elementary or secondary school where the lesson for the formation of the pupils for their instruction and their education is exempted". It can be a question either of only a preschool, primary or secondary level, or of a unit joined together in school complex. From this point of view, we think that a school is an institution or recognized establishment of public utility, the second educational medium par excellence, intended for the teaching and the training of knowledge. Any school at the primary education or secondary level, counts a complete cycle of studies and at least six distinct classes. It is directed by a school principal who is the manager and administrator.

The teaching or education is an industry which employs many important human and material resources (Coombs, 1985) [23]. In the competition with other industries proportionally employing more reduced labor, whose productivity increases regularly, teaching will always be outdistanced and by far until improves its output and the productivity of all the specialists that it employs. However, teaching, nobody doubts, is today part of the large companies of production. It even became, according to Coombs (1985) [23], one largest of the na- 
tional companies.

The school is also a form of company laying out the various resources, a vision, a goal, a mission, objectives and a determined mandate, it cannot function without being organized, directed (managed), controlled and coordinated. Thus, in a school company, one sees intervening of the quantitative and qualitative elements which make it possible to achieve its goals. To arrive there, two operations thus intervene like scientific preconditions of existence of a company also of a school: design and the realization. Concession (organization) with the realization (operation or management) of a school company, the school manager is based on the modern considerations of management following:

- A school must fall under the continuation of the objectives well defined in a plan prepared for this purpose;

- A school, school company, one finds all kinds of the supplies in hand there in other companies out-of-school, (Kidinda, 2005) [24];

- A school is an establishment or an institution which accommodates learning them and in which is given a mainstream education or is specialized. It goes thus there from the private schools and the public schools, the elementary schools and the secondary schools;

- A school is a service or company or industry of production (Coombs (1985) [23];

- A school must consequently base its management (operation) and its organization on the principles and scientific constraints of management which proved reliable in other service companies and of production (Le ThanhKhoi, 1971) [25].

Ultimately, according to Framework-Law of the National Teaching (RD Congo-MINESP, 2014) [22], is considered private school, any private establishment of education maternal, primary, secondary or professional to create by "any natural person or morals, Congolese or foreign who presents the warranties civic, legal, financial, material, morals, teaching, and ragogic, administrative and environmental defined in articles 49 to 52 of this law" (article 45), and is approved by the decree of the Ministry of Central government having teaching in its attributions or by the Governor of province (Article 40).

\subsection{Life Cycle Model of an Organization}

In the popular culture, the company is readily compared with an organization or human life. In the theoretical cognitive one, the phenomenon was described of projection or metaphor. Frois (1997) [26] states that as human, each "company has a life cycle, comprising stages of development, of which design, gestation, birth, growth, decline and death" In the life cycle described by the economists, the birth corresponds to the launching of a company; youth with the growth and adolescence correspond to periods of expansion and turbulence of the company; the adult period and old age, correspond to a maturity of the company in an environment, followed by a decline, until death even the renewal (Lakoff and 
Johnson, 1980) [27].

Several models of life cycle were established. Among we refer to the model of Hersey, Kenneth and Blanchard (1972) [1]; the model of Chandler (quoted by Luboya, 2014) [2] and the model of Quinn and Cameron (1983) [4]. For the need of explanation, we will provide the efforts of synthesis of various the models in order to emphasize a model of contingency. The strategic analysis makes it possible to detect various causes of vulnerability of the company and enlighten its future by bringing closer the characteristics to its environment of its competences, thanks to an analysis of its environment and chain of value.

In the same way, the bringing together of the theory of the life cycle of the product, or the activity at their stage of development is a tool for strategic analysis, since each phase of the cycle is related to strategic actions. Being based on the theory of the life cycle of a company, each phase of this cycle is associated with a cause of particular failure (Saporta, 1994) [6]. The survival of the company depends on its capacity to mobilize the resources of its internal and external environment. Many studies suggest five phases of the life cycle of an Organization. There is launching or birth or foundation, the Growth or youth, the Maturity or stabilization and Decline and death. The management which was to be the best as in the previous phase does not know or is not laid out to change or mobilize the strategies to get better results. This simple truth was shown in a study of 2003 of 1900 professionals who help the companies in difficulty. Among the causes of the decline, this study indicates relatively: Too many debts (28\%); the insufficiency of leadership (17\%); bad planning (14\%); the defect of change (13\%); the inexperienced ones in management (11\%); not enough income (9\%) and accidental causes (8\%) (Koenig, 1991) [7].

\section{Methodology}

\subsection{Research Design}

This study is inspired and classified between the epistemological paradigm positivism and constructivism. In view of the category and to the orientation, this study is applied in the mixed methods including the qualitative and quantitative approach, at a descriptive, analytical and exploratory. Referring to the research classification system in science of the education (Ellis and Fouts, 1993, 2nd ed. 1997; Grossen, 1998a; Grossen, 1998b) [28] [29] [30], this study is classified among the second level studies (testing of the theoretical model).

This study uses triangulation approach (Sardan, 2008; Ngongo, 1999; Denzin, 2006; Rothbauer and Paulette, 2008) [31] [32] [33] [34]. The first is centered on the triangulation of the sources, of the theoretical and practical data collected. These are the relevant information received from many sources in particular of school experiencing failure principals, promoters and teachers and various schools reports and documentations. Second is required the triangulation of the research methods returns to the use of the methods of survey, biographical and observation, (Crutzen, and Van Caillie, 2007a; Tashakkori and Teddlie, 2010) 
[35] [36]. And finally, the forth is directed the triangulation of the techniques of data-gathering (the questionnaire, taking notes and the collective and individual semi-structured interview with programing and no programing appointments), of data processing (the statistical analysis: percentages, mean, chi square, and analysis of contents) and that of interpretation of the results. It is the theoretical framework, simple description and the induction-deduction (Creswell, 2014) [37].

\subsection{Population and Sample}

The present study is spread out over a period going from 2014 to 2015. It sides to specify that the exploited data are those from the five years (from 2007 to 2012). The pre-school, primary and secondary school in Kinshasa, precisely those administrated and controlled by the educational Province of Kinshasa-West.

In the population of 217 schools in bankruptcy for the period surveyed of 2007 to 2012, we extracted a probability sample, Stratified Random Sampling of 140 schools, that is to say 420 subjects of three levels of the operation of a school (140 participants respectively ex-teachers, ex-promoters and ex-chiefs of establishments for perfect balances) with $95 \%$ of confidence and lower than $5 \%$ the risk of error taking into account the size of sample according to the Mayer et Quellet (1991) [38] advices. On 140 private schools experiencing failure, it proves that:

- Under-educational province of Mont-Ngafulaaccounts 14 private schools in bankruptcy (9.7\%) including $0.9 \%$ of the maternal level; $2.8 \%$ of the primary education; $1.4 \%$ from secondary and $4.6 \%$ of a whole school complex.

- The under-province of Selembao contains 45 private schools in bankruptcy $(31.8 \%)$ including $1.4 \%$ of the maternal level; $5.2 \%$ of the primary education; $8.1 \%$ from secondary and $16.1 \%$ of a whole school complex.

- That of Bandalungwa has 28 private schools in bankruptcy (20.3\%) including $46 \%$ of the maternal level; $4.6 \%$ of the primary education; $2.3 \%$ from secondary and $12.9 \%$ of a whole school complex.

- The private schools in bankruptcy of the under-province of Ngaliema are 29 units, that is to say $20.74 \%$ including $0.92 \%$ of the maternal level; $6 \%$ of the primary education; $2.76 \%$ from secondary and $11.06 \%$ of a whole school complex.

- The under-province of Gombe point of disjunction 24 private schools in bankruptcy (17.51\%) including $0.46 \%$ of the maternal level; $2.76 \%$ of the primary education; $1.84 \%$ from secondary and $12.90 \%$ of a whole school complex.

According to the characteristics of participants, we noted that the seniority of the participants from the schools experiencing failure varies between 0 to 15 years: From 7 to 10 years (53.1\%); from 4 to 6 years (31.4\%); from 0 to 3 years (10.5\%) and from 11 to 15 years (5\%). The educational level of participants: Bachelors (40.1\%), Under-Graduate (31.3\%), State Diploma or Certificate of High School (22.2\%) and others level of education (short cycle) (6.4\%). And the func- 
tion exerted in the school experiencing of failure: 140 subjects, is $33.33 \%$ were respectively promoters, schools principals and teachers.

\subsection{Data Collection Instruments, Variables and Materials}

We useda sequential exploratory mixed methods design to collect both quantitative and qualitative data, analyzes them separately. The quantitative component is primary and is used to test school life cycle theory. The qualitative component is used in the service of the quantitative in that it "tests out" ideas generated from the quantitative component. The findings are compared the results to see if the findings confirm or disconfirm each other (Hesse-Biber and Nagy, 2010; Creswell, 2014) [37] [39].

\subsubsection{Qualitative Data (Secondary Data)}

The qualitative data are those collected by the interviews individual and collective, the answers to the closed or open questions, semi-open question and the consulted reports of the private schools experiencing failure surveyed.

They are the internal documents such as official reports resulting from meetings of school management committee, reports of re-entry or opening and end of school years and other types of correspondences dispatched with under-educational raising the problems or the reasons of the failure, the reports and repertoires of the schools the different ones under educational provinces from Kinshasa western and informing about the life cycle from the schools were analyzed. Official documents related to the organization and the operation of private schools experiencing failure also were consulted, analyzed and exploited. The recourse to these various official documents made it possible to make adjustments of remarks collected by interview taking notes. We interviewed 40 advisors including 5 under-provincial chiefs, 20 inspectors of teaching because of 4 per pool, 15 agents of the services of planning and statistics because of 3 by under educational province (school district).

Interview also was the best instrument adapted to identify all of interview the private schools experiencing failure of the educational province western Kinshasa for the period going from 2007 to 2012, to collect information related near the subject-sources but also to trace their repertoire by announcing the names of the establishment and the promoter, the address and the year of creation. In certain circumstances, we use interview to collect the factors of the school failure and the stage of life cycle. Individual Interview on the one hand and collective Interview on the other hand, also were used as principal instruments to collect the secondary data of the study. Collective maintenance enabled us to triangulate the data.

With regard to the method of the collection of the data during these talks, we proceeded, on the one hand, with their catch of note, on the other hand, with their recording thanks to an already prefabricated grid.

From the point of view groups, we held seven collective interviews: two semi structured interviews by no programing and five interviews by programming in 
time frame from Friday, February 8 on May 26th, 2015. During these individual or collective interviews, the principle of saturation for the documents and the interviewers was dislocated (Sardan, 2008) [31]. Three types of saturation are used according to Thietart et als (1999) [40] advices. The first, of empirical type, is that by which we judged that the last documents, interviews or observations do not bring any more sufficiently new or different information to recall the various models of life cycle of the studied schools. The second, of a theoretical nature, asserted himself in us when, afterwards successive analyses and document retrievals, the data do not add any new property to the conceptual and theoretical framework already built, we judged the concepts and theories were saturated. The third and the last, it is the redundancy or repetition of information and lack of innovation in the points of view of the people interviewed (from 30 to 40 subjects with same information).

Ultimately, the secondary data collected enabled us to constitute our sample, to improve the second version of the questionnaire but also to supplement the data collected by the questionnaire especially in the description and categorization of life cycle of the schools according to the characteristics of the various stages.

\subsubsection{Quantitative Data (Primary Data)}

The quantitative data is those coming from the answers to closed and half-closed questions of our survey. We applied the method of investigation in two phases. It is the phase of the pre-investigation and the investigation.

On August 12th, 2015, we were already on the ground for the meadows investigations provided with our first version of the questionnaire and the letter of those and access authorization to the schools in bankruptcy which was delivered to us by the University on the one hand of the line authorities of the educational province on the other hand.

In the phase of the pre-investigation, first version of questionnaire was designed on the literature review, our theoretical model and our questioning of the problems. The reading of documents and the exploitation of reports help us to identify the variables concerned. We tested this first version of questionnaire on ten subjects or participants.

The second and final version of the questionnaire resulted from the first one after the exploitation of the data collected with the pre-investigation. The analysis of these data compared to our assumptions and our ideal model enabled us to direct the items of our first version of the questionnaire, to delimit them, select them, make them clearer, simple and comprehensible. This version comprised for the part of the fundamental questions 40 questions. 13 closed either with multiple choices, or with binary choice, 15 halves closed or opened and 12 open. The consistency and the validity of our final questionnaire were tested with the coefficient of Alpha of Cronbach (0.96), that is to say a very high significance (0.20) of Kuder-Richardson estimated (0.97) and the coefficient of variance (1257). 
Our questionnaire comprise of questions of identification. These questions aimed at detecting the profile of the surveyed companies (4 closed questions) on one hand and those which aim at specifying the characteristics of its presenters (4 open-ended questions) on the other hand. These questions relate primarily to the environment, type of life cycle or age, level of organized teaching, size of these surveyed schools. But also of the level of studies of the subjects, their seniority and their rank or exerted function. It is made up of eight questions. Fundamental questions on the life cycle of the school count 8 questions ( 3 closed and 5 open). They inform us about and the decline creation date of the school, the characteristics of a school to its creation, its youth, its maturity, its decline and its death and the prospects for the actors after death and the consequences of the disappearance of a school to short, in the medium and long term.

The phase of investigation helps us to collect the dependents variables which are composed of opinions from 420 subjects on the life cycle of the schools and their factors of bankruptcy. They are analyzed answers of our protocols of investigation or notes of the individual or collective interviews. The independent variables comprise of the environment (favorable, rather favorable and unfavorable); the Size (size intermediate with 21 to 4999 units and small and average schools with less than 21 agents. No school is classified among the big size of the companies. Age and type of life cycle: In the long term (48.6\% of the schools), in the medium term ( $47.9 \%$ of the schools) and short-term (53.5\% of the schools) and the organized Level of education were retained: schools organizing the levels maternal, primary and secondary (57.2\% of the schools), school organizing only one primary education level (21.4\%), schools organizing only one secondary level $17.1 \%)$, school organizing only one maternal level (4.3\%). And the intermediary variables are death of surveyed targeted, promoters or managers of schools, absence of traces; the unhappy circumstances or exceptional circumstances (loss of the local school archives of the school, migration of one surveyed, its refusal to collaborate in the investigation).

\subsection{Data Management and Analysis Procedures}

We managed our questionnaire 420 subjects of the 140 schools in bankruptcy individually targeted. The operation of the administration as a whole had taken at most six months, more precisely from September 02nd to December 20th, 2014 then from January 20th to March 28th, 2015. With an aim of anticipating the question of experimental mortality (not filling and loss of the questionnaires), we really managed the questionnaire on the 483 subjects, therefore 167 schools with a margin of forecast of 63 subjects, is $15 \%$ in order to avoid miscalculations of the random or probabilistic sampling.

The collected qualitative data were subjected to the analysis of contents (the recording or sorting of mode of expression, categorization, the quantification with the taking into account of the units of analysis). The quantitative information was analyzed by the statistical analysis by the calculation of the frequencies, percent, the arithmetic and geometrical mean but also the calculation of the 
khi-2 in order to test the relation or influences (significant or not) between the variables using the AnaStats software with threshold of 0.05 , that is to say $5 \%$.

\subsection{Anticipated Ethical Issues in the Study}

Several exchanges were made with the competent authorities during the months of July and August 2014. Then a number of official documents established by the academic authorities, of the Ministry of Primary, Secondary and Professional Education and of the school entities decentralized on the level of each province and under educational province were acquired to guarantee our research on the ground. With our request, the under-provincial chiefs put to us in liaison with the chief of pool of inspection of teaching and the department heads of planning and statistics of their district. It is through this "system of sponsorship" (Baumard et al. 2003) [41] or of "the effect of channel" and "contact personalized" (Bertaux, 1980) [42] which we established of the contacts with the chiefs of pool of inspection, the department heads of statistics and planning to enable us to reach the promoters, managers and teachers of the schools in bankruptcy. These chiefs were thus put at perfect of the objectives of our work.

The Measures of ethics were taken. It is a question of privileging the direct and indirect administration questionnaire and its anonymity. Individual maintenance in an atmosphere at the same time of "interaction" and "conversation" between us and the advisors (inquired or interviews) in a familiar fashion of communication in order to put to them in confidence and we avoided the questions of judgment and charge of the responsibilities for the fault of the schools to our interlocutors.

\section{Results and Discussion}

\subsection{Finding}

In RD. Congo, the scarcity of the offer of education, the illiteracy of the Congolese population does not cease increasing. According to investigation report on children and teenagers behind Congolese school, it estimated about "7,375,875 children and teenagers of 5 - 17 years, or $28.9 \%$ of Congolese children. Compared to the results extrapolated of the investigation, it estimates about 3,509,252 children (6 - 11 years old)stand behand school (RD Congo-EDEA, 2012) [9].

The RD. Congo being in the incapacity to cover the whole need in education and to reduce the extent of illiteracy liberalized the educational sector. The liberalization of this sector materialized by the provisions of the framework-law of national teaching of 1986 and 2014 in its articles 49, 51, 52 and 53 (RD Congo-MINESP, 2014) [22]. Consequently, the private schools were created and approved on all the extent of the Republic. Following the permanent economic crisis, the lack of implementation and control of legal provisions of this law and the absence of accompanying measure, the creation and agreement of these private schools took the trend of the proliferation in the province city of Kinshasa. 
With respect of official statistics, there are in primary education 3542 private schools of which more half in the provinces of Kinshasa (1545 schools), Eastern Kasaï (503 schools) and of Katanga (478 schools). In secondary education, there are approximately 2148 private schools of which even more half are always in the provinces of Kinshasa (894 school), of Katanga (294 schools) of Eastern Kasaï (247 schools) (RD Congo-EDEA, 2012) [9]. It should be noted that each year, in each educational Province on average 20 private schools disappear.

In front of the bankruptcy of a significant number of the schools, we were interested to study these observable facts. As we know that these schools voluntarily did not indicate to close their door and to disappear as quickly as the idea which caused their creation. And no authority competence of their school entity decentralized to wish this disappearance. After our investigations, analyses and discussion of the results, we noted:

From the point of view of the duration, these school in bankruptcy lived three categories of life cycle (Figure 1): The short-term cycle (from zero to one year of life) (4\%); the medium-term cycle (from two to five years of life) (48\%); and the long-term cycle (more than five years of life) (48\%).

The biographical and quantified data analyzed (Figure 2) report that, $100 \%$ of schools experiencing failure have lived the phase of birth, starting or launching; $78 \%$ have lived the phase of growth or blooming; $67 \%$ are arrived to maturity or stabilization. $100 \%$ of these schools were the decline or failure then death or disappearance and only $17 \%$ of them have arrived in renewal or rebirth.

From the point of view the stages or phases of life cycle, a categorization emerges from our analysis (Figure 3).

The five types of life cycle of school (Figure 3 ) were lived according to the steps:
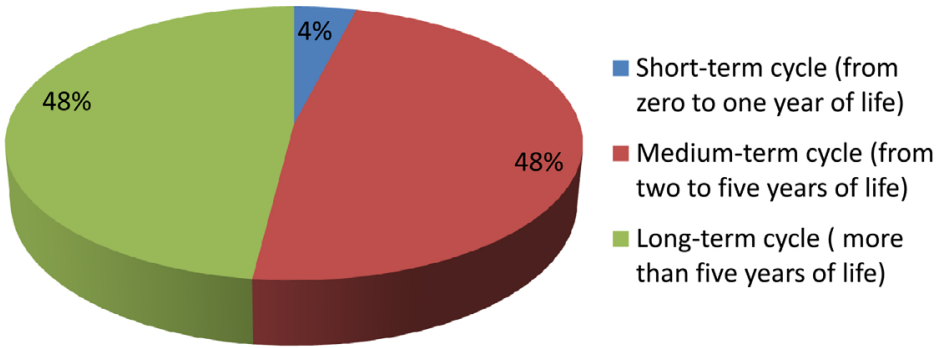

Figure 1. Three categories of life cycle of school in duration perspective.

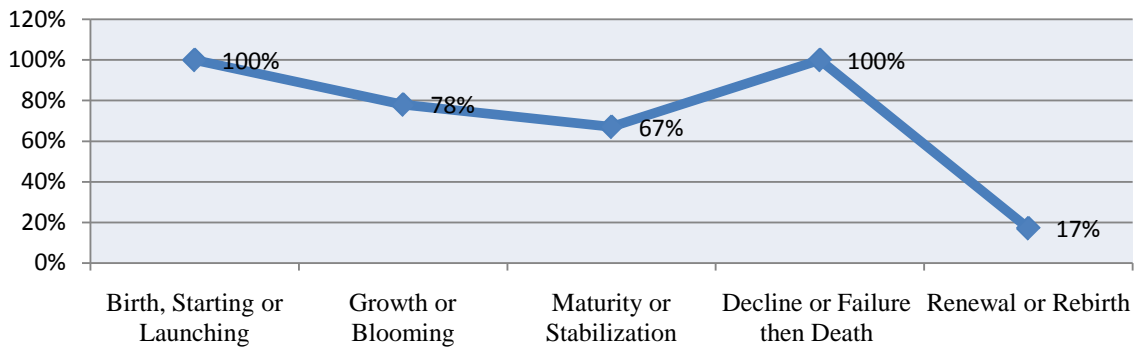

Figure 2. The life cycle of school in stages lived perspective. 


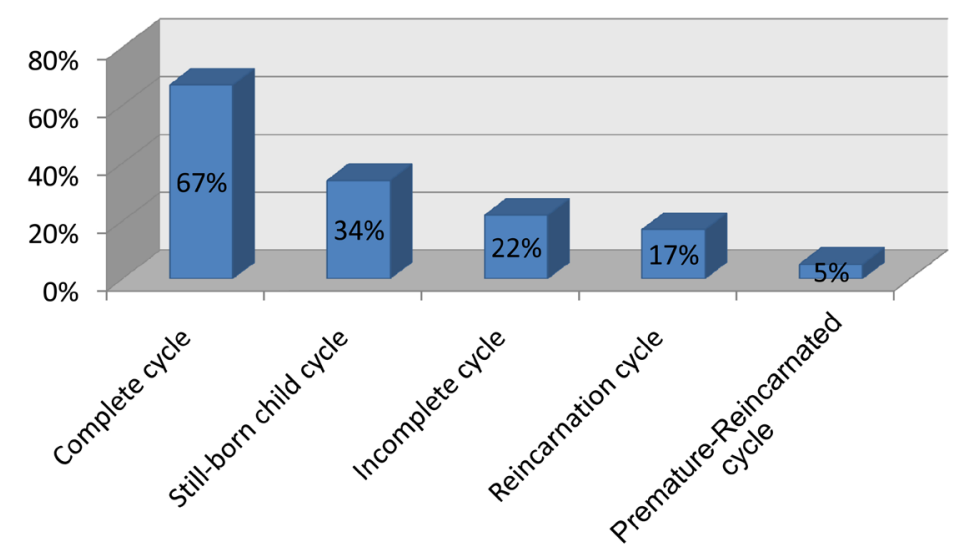

Figure 3. Categorization of life cycle of school according to the stages.

- First category: the schools (67\%) are classified having lived the complete life cycle, i.e. launching, blooming, stability or the apogee, the fall or failure then disappearance or closing (complete cycle);

- Second category: the schools (34\%) are fumed having lived the life cycle still-born child, and forwarded birth with the dead decline then (still-born child cycle);

- Third category: the schools (22\%) come having lived the irregular and incomplete life cycle, and started from birth, growth, dead decline then (incomplete cycle);

- Fourth category: the schools (17\%) are classified having lived the life cycle known as reincarnation which left the birth, the growth, maturity, the dyed decline then and the rebirth (reincarnation cycle);

- Fifth category: the schools (5\%) are classified having lived the premature and which been reincarnated life cycle, and climbed birth with death then rebirth (premature-reincarnated cycle).

As regards explaining the factors of the failure of these schools, many factors were found. We categorize these factors in four groups. We found in order of importance (Figure 4).

The factors of the failure dependent on the management of schools operation and its resources $(68 \%)$ include the problems of financial management; the problems of teaching management, the problems of administrative management where also the problems of administrative management are classified in general, problems of the human stock management (the process of recruitment and its constraints, staff training, the system of remuneration and its power motivational, the system of evaluation, the work conditions, promotion, the management system of the careers of staff), problems of managerial incapacity of the leaders; problems of patrimonial management and problems of marketing strategy. Broadly these problems do not depend on the seniority, the level of studies and the assumed function of the presenters of these schools. However, the problems of incapacity of leaders depend on the assumed function.

The factors related to the schools organizational climate and culture $(22 \%)$ are 


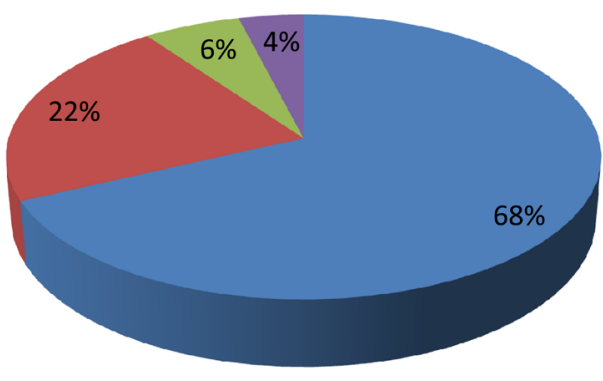

- Problems of Management of schools operation and its resources

- Problems of schools Organization climate and culture

Problems of conditions of school creation and respect of legal dispositions

Exceptional situations and unforeseeable

Figure 4. Problems of failure of private schools.

those relating to the problems of financial organization; administrative; teaching and material organizational. These problems do not depend on the seniority, of the level of studies and on the function assumed by the subjects but also either do not depend on the environment, the size, the life cycle or the duration and the level of education organized by these schools.

Factors of failure related to the conditions of creation and respect of legal dispositions of these private schools (6\%) in particular problems of motivation of promoters during the creation of a school; problems of the site, establishment and respect of the official standards and problems of respect of the legal tendencies. These problems depend significantly on the environment, the size, the life cycle or duration and the level of the teaching of their school company. Statistically, these problems do not depend significantly on the seniority or working experience, the level of studies and the function assumed by subjects.

Factors of failure related to the exceptional situations and unforeseeable (4\%), it was retained the problems of the local and national educational policy; socio-economic problems of the country and the problems of management of the unforeseen ones. These problems do not depend significantly on the seniority, the level of studies and the assumed function.

The similar results were also raised in the studies on the bankruptcy of the marketing companies and industrial carried out by many researchers (Argenti, 1976; Ooghe and Waeyaert, 2004; Liefhooghe, 1997) [43] [44] [45]. These kinds of difficulties leading the organizations to the bankruptcy were also frequently evoked in the literature on the questions of bankruptcy (Argenti, 1976; Ooghe and Waeyaert, 2004; Liefhooghe, 1997) [43] [44] [45] as in the studies on the factors having an impact on the success or the failure of the company.

Compared to the model of contingency describes in the ideal model, our study highlighted five life cycles lived differently by the targeted schools and some explanatory factors of the bankruptcy of these schools. In the discussion, it is released between categorization from lived life cycles and the independent factors from the bankruptcy from these schools (Appendix Table A1).

\subsection{Scientific Contributions of the Study}

A three dimensional exploratory approach was successfully used in the present 
study. It encompasses theoretical, methodological and managerial methods.

\subsubsection{From the Methodological Point of View}

To our knowledge, this is the first time a triangulation approach is used in the analysis of explanatory factors of the failure and life cycle of the Congolese private schools. This approach is used successfully in other scientific disciplines, which encouraged us to opt for it.

This study applied between positivism and the constructivism in a new approach in social sciences and of management, the triangulation. It resorted to the triangulation of the data sources, the methods and the techniques of collection, data processing and interpretation. Our results guarantee the generalization of the results for the entity educational targeted (95\% from confidence and 5\% of risk of error taking into account the size and of the type of sample (Mayer and Quellet, 1991) [38] and taking into account the validity of the instrument of data collection with the use of coefficient alpha and of formula 20 of Kuderand Richardson, (1937) [46] and Lee Cronbach (1951) [47]; the rate of survey, experimental mortality; measurement Independence and dependence of the variables of research (with the coefficient $\mathrm{V}$ to be on fire); confidentiality and ethical consideration, validity and relevance of the primary and secondary data.

\subsubsection{From the Theorization Point of View and Managerial}

The practical contributions of our study are at three levels:

The managers and the investors have a description of the practical information as regards indicators of the school experiencing failure. That enables them to carry out a comparative diagnosis their own factors of bankruptcy. So, the decision maker finds a contribution within our work, giving him the possibility of taking account of the whole of the factors in the analysis of the failure, bankruptcy, the reduction of the uncertainty of the environment and the improvement of control and coordination between the various actors of the school company. By consequence, the improvement of the comprehension of the phenomenon of the bankruptcy will help the educational actors with better anticipation of the risk of bankruptcy.

Particularly, our study forged the expression "problems or difficulties" to design factors or causes of failure and the empirical explanatory theory of the failure of school field or educational sector. This study categorize five lived models of life cycles from the point of view stages (cycle complete, incomplete, still-born child, of reincarnation and premature-which been reincarnated) and three models according to the duration (in the short run, in the medium term and long-term); the instrument panel for the study of contingency enters the environment, the life cycle, the size, the levels of education organized and the explanatory factors of the bankruptcy of the school companies on the one hand; the synoptic table of characteristics or behaviors of each phase of life cycle of a school company, a kind of alarm;

Taken into account of factors related to the problems of conditions of creation 
of the companies made up of several problems, a manner of analyzing the causes related to the psychoanalytical and antenatal origins (of the design or unconsciousness of the legal or moral person) of the bankruptcy of a school company; factors related on the operation and the management of the school companies and its resources material, human, financial and teaching; factors related to the exceptional situations and unforeseeable; the implication of the seniority, the level of studies; assumed function on the one hand; environment, size, the life cycle and level of education organized in the factors of bankruptcy of the school companies; and factors of success like remedies for the bankruptcy, failure or failure in all the aspects of the management of the school companies.

As for the choice of the characteristics of the selected schools, the effects rising from sample, branch of industry, the size of the schools, are likely to mask certain explanatory factors. Our study is carried out on broad samples, whereas those used in the past were more restricted.

\subsection{Socio-Political and Legal Contributions}

With our opinion, even if the adoption and the promulgation of framework-law of national teaching (RD Congo-MINESP, 2014) [22] seem to be an answer to the problems of the regulation and reforms effective in the creation and the approval of the private schools, it is advisable to highlight the requirements of the warranties civic, legal, financial, material, morals, teaching, andragogic, administrative or managerial and environmental (Article 49, 50, 51 and 52) on the one hand; funding sources while adding in addition to the contribution of the parents, the subsidy of the promoters, of the thirds, products of self-financing, gifts and legacy and subsidies of the central Governor, the provinces or the entities territories decentralized (Article 170) in addition.

The true problem in the massive disappearance of the private schools remains in the national public policy of the framing and the accompaniment of SME or PMI, of the real investment and firm re-enlisting in education of Congolese especially of youth but also of the manifest will in the follow-up of the applicability of the adopted and promulgated official legal and regulatory provisions.

Our fear of the bankruptcy of the schools working within such legislative framework and organizational lies in the logic of "same causes produce the same effects". It is to say that the Congolese State creates and approved schools which supposed and are intended for disappearance and/or the early bankruptcy. This situation rises in our spirit a questioning: will that of knowing how the Congolese nation achieve the goal of the millennium of education for all? Which objective aimed at the reduction of the extent of the school loss, unhooking, and illiteracy; and the cover of the increasing request of education thanks to an adequate offer while building, while creating and by approving viable school?

The bankruptcy of the educational establishments predicts the failure of this objective. This prediction is justified in the manifest incapacity of the State to cover only the request of the education of the Congolese on the one hand and to 
frame the private schools which try to help it in its weaknesses on the other hand.

It is not enough to liberalize the educational sector dealing with the problems of supply and demand of education, but rather to liberalize it by keeping a glance guide, critical and sanctioned on the schools born of the action liberator of the Power-organizer in the applicability of the law in order to guarantee to the educational operators the climate cleansed and favorable to the investment. It is in this direction that the Congolese State will keep its role and its function of the organizing Power.

\subsection{Limits and Research Perspectives}

This study did not approach in-depth all the purely economic and financial aspects of the bankruptcy of the school companies. It is also necessary to note the unavailability of certain information which could have made it possible to enrich the study, the problem of the data within the base of the data used and impossibility of conducting a survey near all the entrepreneurs (promoters) failed.

Its results are particular at the private schools of Kinshasa and cannot be generalized with the whole private school of DR Congo but this study gives the databases likely to switch the later studies on this field.

Which are the exits for future research? The studies of the life cycle and factors of the failure of the private schools in other provinces of the DR Congo or in continental and international perspectives are encouraged. This study answers only the question which the factors of success, maintenance or survival or management of the effective Congolese school. We think however that these results can be improved, by increasing the sample size, for example the number of the schools composing the sample, by in particular considering data over one longer duration, of qualitative information such as the age of the firms, the experiment of the leaders, the branch of industry. It is obvious that these elements must be introduced into the models, because there is not anymore; doubt that most these qualitative variables play a crucial role in the forecast of the risk of failure (bankruptcy). Another future way of research could relate in particular to the clarification of models of lifetime such as the models of Cox-PLS, which make it possible to envisage the expiry of the bankruptcy.

\section{Conclusions}

The present study offers an overview on the situation of failure of private schools regarding the duration of activities, the typology of life cycle and the stage in life cycle when failure occurs. It is noteworthy to specify that this study was conducted in the context of the crisis which strikes all the economic sectors. The 140 private schools experiencing failure lived:

From the point of view of the duration of life cycle, these schools were lived three categories of life cycle: The short-term cycle; in the medium term and long-term. About biographical data, all of the schools were lived the phase of 
birth and the decline or the failure then death or disappearance. Only few of them was renewed or arrived at the rebirth. And the majority of the schools arrived at the phase of growth and maturity. Considering the degree of preponderance and the inflation of responses of participants, the private schools lived five models of life cycles according to the stages of life cycle perspective: The complete cycle, the cycle still-born child, the incomplete cycle, the cycle of reincarnation and cycles it premature-been reincarnated.

Thus, to explain the factors of bankruptcy of these 140 schools, three groups of factors are identified. They are the factors relating to the conditions of creation of the school companies; with the organization of the schools (organization teaching, administrative, material and financial); with the operation and the management of the schools and of its resources (financial management; teaching and administrative). To the above-mentioned problems those are added related to the managerial incapacity of the leaders; with patrimonial management and the school marketing strategy. And finally, the factors exceptional situations and unforeseeable are also pointed. It should note that opposite each group of these factors below, the brought closer people proposed some remedies likely to reduce, to eradicate the bankruptcy of the schools which we describe as "factors of success of the schools".

These results confirm our first assumption and the second is partly confirmed because the factors related to the conditions of creation depend on the environment, the size, the life cycle and on the organized level of education. And the problems of organization, of school operation and resources management even those of exceptional situations and unforeseeable and different private schools do not depend on it significantly. However, the empirical result seems to make the factors related to operation and management more balancing and projecting follow-ups of those related to the organization then in the conditions of creation and the exceptional situations and unforeseeable in dimension joint committee; those related to the financial organization, with financial management, teaching and administrative, followed by the site, establishment and respect of the standards, and the local educational policy and main road are in dimension intragroup.

\section{References}

[1] Hersey, P. and Blanchard, K.H. (1972) Management of Organizational Behavior: Utilizing Human Resources. Prentice-Halls, Englewood Cliffs.

[2] Chandler, A.D. (1962) Strategy and Structure: Chapters in Life Cycle of an Organization. In: Luboya Tshiunza, A.C. (2014) Study of Factors of Private Educational Establishments of Congo, Master Thesis, National Pedagogical University, Kinshasa.

[3] Adizes, I (1998) Managing Corporate Lifecycles: How Organizations Grow, Age, and Die, Volume I. The Adizes Institute Publications, Santa Barbara.

[4] Quinn, R.E. and Cameron, K. (1983) Organisation: Cycles de vie et certains critères shifting de l'efficacité. West Publishing, Eagan, Minnesota. 
[5] Blazy, R. and Combier, J. (1998) La défaillance d'entreprise: Causes économiques, traitement judiciaire et impact financier. Economica/INSEE Méthodes no. 72-73.

[6] Saporta, B. (1994) La création d'entreprises: Enjeux et perspectives. Revue française de gestion.

[7] Koenig G. (1991) Difficultés d'entreprise et inertie active. Direction et Gestion, 126-127.

[8] Luboya Tshiunza, A.C. (2010) Analysis of Factors of Failure of Company of Urban Transport of Congo. Thesis, National Pedagogical University, Kinshasa.

[9] RD Congo-EDEA (2012), L'enquête sur des enfants et adolescents en dehors de l'école, Unesco.

[10] Ooghe H. and Van Wymmersch, C. (1996) Traité d'analyse financière. 6è Édition, Presses Universitaires de Namur, Paris.

[11] Liang, L. and Wu, D. (2003) An Application of Pattern Recognition on Scoring Chinese Corporations Financial Conditions Based on Back Propagation Neural Network. Computers and Operations Research, 32, 1115-112. https://doi.org/10.1016/j.cor.2003.09.015

[12] Hol, S., Westgaard, S. and Wijst, V.N. (2002) Capital Structure and the Prediction of Bankruptcy. EWGFM Conference, Capital Markets Research (Bankruptcy Prediction) Conference Paper.

[13] Sharabany, R. (2004) Business Failures and Macroeconomic Risk Factors. Discussion Paper 06, Bank of Israel, Research Department.

[14] Abid, F. and Zouari, A. (2001) Predicting Corporate Financial Distress: A Neural Networks Approach. Proceedings of the International Finance Conference, Tunisia, 183-195.

[15] Pompe, P.M. and Bilderbeek, J. (2005) The Prediction of Bankruptcy of Small and Medium Sized Industrial Firms. Journal of Business Venturing, 20, 847-868. https://doi.org/10.1016/j.jbusvent.2004.07.003

[16] Pindado, J. and Rodrigues, L.F. (2001) Parsimonious Models of Financial Insolvency in Small Companies. Working Paper, SSRN Working Paper Series.

[17] Atiya, A.F. (2001) Bankruptcy Prediction for Credit Risk Using Neural Networks: A Survey and New Results. IEEE Transactions on Neural Networks, 12, 929-935. https://doi.org/10.1109/72.935101

[18] Berryman, J. (1982) Small Business Failure and Bankruptcy, a Survey of Literature. European Small Business Journal, 1, 47-49. https://doi.org/10.1177/026465608300100404

[19] (1994) Le Nouveau Larousse encyclopédique. Larousse, Paris.

[20] Julien, P.A. and Marchesnay, M. (1996) L'entrepreneuriat. Economica, Paris.

[21] Mayau, F. (1990) Les facteurs de succès de la création de sociétés de services aux enterprises. Cahiers lyonnais de recherche en gestion, Mai.

[22] RD Congo-MINESP (2014) Loi-cadre n 14/004 du 11 Février 2014 de l'Enseignement National.

[23] Coombs, H.P. (1985) La crise mondiale de l'éducation. De Boeck-Université, Paris.

[24] Shandungo, K. (2005) Principes généraux de management. CRUPN, Kinshasa.

[25] Khoi, L.T. (1971) L'enseignement en Afrique tropicale. Minuit, Paris.

[26] Frois, P. (1997) Entreprise et écologie. L'Harmattan, Paris.

[27] Lakoff, G. and Johnson, M. (1980) Metaphors We Live By. University of Chicago 
Press, Chicago.

[28] Ellis, A. and Fouts, J. (1993) Research on Educational Innovations. Eye on Education, Princeton.

[29] Grossen, B. (1998a) What Does It Mean to Be a Research-Based Profession? University of Oregon, Eugene. http://personalweb.donet.com/ eprice/resprf.htm

[30] Grossen, B. (1998b) What Is Wrong with American Education. In: Evers, W.M., Ed., What's Gone Wrong in American Classrooms, Hoover Press, Stanford, 23-48.

[31] Sardan, J.P.O. (2008) La rigueur du qualitatif. Les contraintes empiriques de l'interprétation socio-anthropologique. Louvain-la-Neuve Academica, Bruxelles.

[32] Ngongo Dishasi, P.R. (1999) La recherche scientifique en education. Academica, Bruxelles.

[33] Denzin, N. (2006) Sociological Methods: A Sourcebook. 5th Edition, Aldine Transaction, Piscataway.

[34] Rothbauer, P.M. (2008) Triangulation. In: Given, L., Ed., The SAGE Encyclopedia of Qualitative Research Methods, Sage Publications, Thousand Oaks, California, 892-894.

[35] Crutzen, N. and Van Caillie, D. (2007a) The Prevention of Business Failure: A State of the Art. Accounting History.

[36] Tashakkori, A. and Teddlie, C. (2010) SAGE Handbook of Mixed Methods Research in Social Science and Behavior Research. Sage, Thousand Oaks. https://doi.org/10.4135/9781506335193

[37] Creswell, J.W. (2014) Research Design, Qualitative, Quantitative and Mixed Methods Approaches. 4th Edition, SAGE, California.

[38] Mayer, R. and Quellet, F. (1991) Méthodologie de recherche pour les intervenants sociaux. Gaetan-Varin, Mantical.

[39] Hesse-Biber, S.N. (2010) Mixed Methods Research: Merging Theory with Practice. Guilford Publications, Inc., New York.

[40] Thietart, R.-A., et al. (1999) Méthodes de recherche en management. 2eme Édition, Dunod, Paris.

[41] Baumard, P., et al. (2003) La collecte des données et pratique de leurs sources. Dunod, Paris.

[42] Bertaux, D. (1980) Approche biographique, sa validité méthodologique, ses potentialités. Cahiers internationaux de sociologie, IXIX, 197-225.

[43] Argenti, J. (1976) Corporate Collapse: The Causes and Symptoms. Holsted Press, McGraw-Hill, London.

[44] Ooghe, H. and Waeyaert, N. (2004) Oorzaken van faling en falingspaden: Literatuuroverzicht en conceptueelverklaringsmodel. Economisch en Sociaal Tijdschrift, 57, 367-393.

[45] Liefhooghe, B. (1997) Causes et mécanismes des faillites d'entreprises : une synthèse bibliographique. Cahiers de la Faculté des Sciences Economiques, Sociales et de Gestion, ${ }^{\circ} 189,1-45$.

[46] Kuder, G.F. and Richardson, M.W. (1937) The Theory of the Estimation of Test Reliability. Psychometrika, 2, 151-160. https://doi.org/10.1007/BF02288391

[47] Cronbach, L.J. (1951) Coefficient Alpha and the Internal Structure of Tests. Psychometrika, 16, 297-334. https://doi.org/10.1007/BF02310555 


\section{Appendix}

Table A1. Contingence between life cycle, environment, size, sectors and factors of school failure.

\begin{tabular}{|c|c|c|c|c|c|c|}
\hline $\begin{array}{l}\text { Life cycle or } \\
\text { Duration }\end{array}$ & $\begin{array}{l}\text { Stages } \\
\text { Criteria }\end{array}$ & Birth & Growth & Maturity & Decline then Dead & Rebirth \\
\hline \multirow{3}{*}{$\begin{array}{l}\text { Complete cycle } \\
\text { (A long and } \\
\text { medium term) }\end{array}$} & $\begin{array}{c}\text { Principal } \\
\text { behaviors } \\
\text { interpreted }\end{array}$ & (1) & (2) & (3) & (4) & - \\
\hline & $\begin{array}{l}\text { Factors of } \\
\text { success }\end{array}$ & $\begin{array}{c}\text { Respect of } \\
\text { standards of good } \\
\text { governance of the } \\
\text { schools and its } \\
\text { resources; }\end{array}$ & $\begin{array}{c}\text { Size, } \\
\text { Increase in } \\
\text { numbers of } \\
\text { pupils }\end{array}$ & $\begin{array}{l}\text { Increase in } \\
\text { sections of } \\
\text { teaching }\end{array}$ & - & - \\
\hline & $\begin{array}{l}\text { Factors of } \\
\text { failures }\end{array}$ & $\begin{array}{l}\text { Environment, size } \\
\text { and organized } \\
\text { level of education }\end{array}$ & $\begin{array}{c}\text { Technical } \\
\text { Problems of } \\
\text { management } \\
\text { Environment and } \\
\text { bad political of } \\
\text { internal } \\
\text { governance }\end{array}$ & $\begin{array}{l}\text { Environment and } \\
\text { good policy of } \\
\text { internal and } \\
\text { external } \\
\text { governance }\end{array}$ & $\begin{array}{l}\text { Problems of the } \\
\text { creation of } \\
\text { organization, } \\
\text { management of the } \\
\text { company and its } \\
\text { resources } \\
\text { Exceptional } \\
\text { situations and } \\
\text { unforeseeable }\end{array}$ & - \\
\hline \multirow{3}{*}{$\begin{array}{l}\text { Irregular or } \\
\text { incomplete cycle } \\
\text { (A long and } \\
\text { medium term) }\end{array}$} & $\begin{array}{l}\text { Principal } \\
\text { behaviors } \\
\text { interpreted }\end{array}$ & (1) & (2) & - & (4) & - \\
\hline & $\begin{array}{l}\text { Factors of } \\
\text { success }\end{array}$ & $\begin{array}{c}\text { Respect of } \\
\text { standards of good } \\
\text { governance of the } \\
\text { companies and its } \\
\text { resources; }\end{array}$ & $\begin{array}{c}\text { Size } \\
\text { Increase in } \\
\text { numbers of } \\
\text { pupils }\end{array}$ & $\begin{array}{l}\text { Increase in } \\
\text { sections of } \\
\text { teaching }\end{array}$ & - & - \\
\hline & $\begin{array}{l}\text { Factors of } \\
\text { failures }\end{array}$ & $\begin{array}{l}\text { Environment, size } \\
\text { and organized } \\
\text { level of education }\end{array}$ & $\begin{array}{c}\text { Technical } \\
\text { Problems of } \\
\text { management } \\
\text { Environment and } \\
\text { bad political of } \\
\text { internal } \\
\text { governance }\end{array}$ & $\begin{array}{l}\text { Environment and } \\
\text { good policy of } \\
\text { internal and } \\
\text { external } \\
\text { governance }\end{array}$ & $\begin{array}{l}\text { Problems of the } \\
\text { creation of } \\
\text { organization, } \\
\text { management } \\
\text { of the company } \\
\text { and its resources } \\
\text { Exceptional } \\
\text { situations and } \\
\text { unforeseeable }\end{array}$ & - \\
\hline \multirow{2}{*}{$\begin{array}{l}\text { Cycle of } \\
\text { still-born child } \\
\text { (In the short } \\
\text { run) }\end{array}$} & $\begin{array}{c}\text { Principal } \\
\text { behaviors } \\
\text { interpreted }\end{array}$ & (1) & - & - & (4) & - \\
\hline & $\begin{array}{l}\text { Factors of } \\
\text { success }\end{array}$ & $\begin{array}{c}\text { Respect of } \\
\text { standards of good } \\
\text { governance of the } \\
\text { schools and its } \\
\text { resources; }\end{array}$ & - & - & - & - \\
\hline
\end{tabular}




\section{Continued}

Factors of failures

Principal

behaviors

interpreted

Factors of success

Cycle of

reincarnation

(In the long run)
Factors of failures behaviors interpreted

Factors of success

Cycle prématuré et réincarné

(A court terme)
Environment, size and organized level of education

Respect of standards of good governance of the companies and its resources; Environment of learning and size and educational organized level

Problems of the governance of the schools and its resources; Environment of learning and size and educational organized level

Respect of standards of good governance of the companies and its resources;

Environment, size and organized level of education

Bad motivation and problem of creation.

Factors of failures
Bad definition of vision, mandate, goal and objectives
Problems of the creation, organization, management of the school and its resources Exceptional situation

$s$ and unforeseeable

$\begin{array}{cc} & \text { Add to } \\ & \begin{array}{c}\text { educational level } \\ \text { or options }\end{array} \\ \text { Size, Increase in } & \text { Environment and } \\ \text { numbers of } & \text { good policy of } \\ \text { pupils } & \text { internal and } \\ & \text { external } \\ & \text { governance }\end{array}$

Technical problems of management Environment and bad political of internal governance
Abusive addition of educational level

Bad management of finances
Problems of the creation, organization, management of the schools and its resources Exceptional situations and unforeseeable
Research of partner and the acts of authorization
(5)

Research of partner and the acts of authorization

Legend: 1) Characteristic of the birth (1). 2) Characteristic of the youth (2). 3) Characteristic of the growth (3). 4) Characteristic of the decline and died (3). 5) Characteristic of the rebirth (3). 